\title{
A Survey to Determine Decision-Making Styles of Working Paramedics and Student Paramedics
}

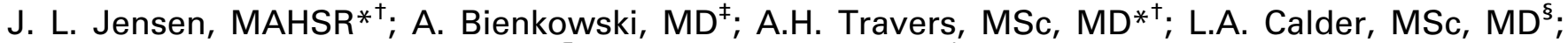 \\ M. Walker*; W. Tavares, ACP, PhD"; P. Croskerry, PhD, $\mathrm{MD}^{\dagger}$
}

\section{ABSTRACT}

Objective: Two major processes underlie human decisionmaking: experiential (intuitive) and rational (conscious) thinking. The predominant thinking process used by working paramedics and student paramedics to make clinical decisions is unknown. Methods: A survey was administered to ground ambulance paramedics and to primary care paramedic students. The survey included demographic questions and the Rational Experiential Inventory-40, a validated psychometric tool involving 40 questions. Twenty questions evaluated each thinking style: 10 assessed preference and 10 assessed ability to use that style. Responses were provided on a five-point Likert scale, with higher scores indicating higher affinity for the style in question. Analysis included both descriptive statistics and $t$ tests to evaluate differences in thinking style. Results: The response rate was $88.4 \%$ (1172/1326). Paramedics ( $n=904$ ) had a median age of 36 years (IQR 29-42) and most were male $(69.5 \%)$ and primary or advanced care paramedics $(P C P=55.5 \% ; A C P=32.5 \%)$. Paramedic students $(n=268)$ had a median age of 23 years (IQR 21-26), most were male $(63.1 \%)$ and had completed high school $(31.7 \%)$ or an undergraduate degree $(25.4 \%)$ prior to paramedic training. Both groups scored their ability to use and favourability toward rational thinking significantly higher than experiential thinking. The mean score for rational thinking was 3.86/5 among paramedics and $3.97 / 5$ among paramedic students $(p<0.001)$. The mean score for experiential thinking was $3.41 / 5$ among paramedics and $3.35 / 5$ among paramedic students $(p=0.06$ ).

Conclusion: Working paramedics and student paramedics prefer and perceive that they have the ability to use rational over experiential thinking. This information adds to our current knowledge on paramedic decision-making and is potentially important for developing continuing education and clinical support tools.

\section{RÉSUMÉ}

Objectif: Deux grands processus sous-tendent les prises de décision chez l'homme : la pensée expérientielle (intuitive) et la pensée rationnelle (consciente). Toutefois, I'on ne sait pas à quel mode de pensée recourent principalement les ambulanciers paramédicaux et les étudiants en technique paramédicale dans leurs prises de décision d'ordre clinique.

Méthode: Une enquête a été menée parmi des ambulanciers paramédicaux et des étudiants en soins préhospitaliers de base. Le questionnaire se composait d'une collecte de données démographiques ainsi que d'un outil psychométrique validé de 40 questions, le Rational Experiential Inventory-40 (inventaire rationnel-expérientiel). Vingt questions portaient sur chacun des modes de pensée : dix sur le mode de prédilection et dix sur la capacité d'utiliser ce mode. Les réponses étaient cotées sur une échelle de Likert à 5 points, et les scores plus élevés indiquaient une préférence pour le mode en question. Une analyse s'appuyant sur des statistiques descriptives et des tests $t$ a été réalisée afin de faire ressortir les différences entre les modes de pensée.

Résultats: Le taux de réponse a atteint 88,4\% (1172/1326). Les ambulanciers paramédicaux $(n=904)$, d'un âge médian de 36 ans (écart interquartile [EIO] : 29-42), étaient pour la plupart des hommes $(69,5 \%)$ et ils avaient une formation en soins préhospitaliers de base ou avancés (base $=55,5 \%$; avancés $=32,5 \%)$. De leur côté, les étudiants en technique paramédicale ( $n=268$ ), d'un âge médian de 23 ans (EIQ : 21-26), étaient pour la plupart des hommes $(63,1 \%)$ et ils avaient terminé leurs études secondaires $(31,7 \%)$ ou avaient obtenu un diplôme de premier cycle $(25,4 \%)$ avant leur formation en technique paramédicale. Dans les deux groupes, les répondants ont indiqué une préférence marquée pour le mode de pensée rationnelle comparativement au mode de pensée expérientielle, et se sont dits capables de l'utiliser. Le score moyen pour la pensée rationnelle s'élevait à 3,86/5 chez les ambulanciers paramédicaux et à $3,97 / 5$ chez les étudiants en technique paramédicale $(p<0,001)$, tandis que le score moyen pour la pensée expérientielle était de $3,41 / 5$ chez les ambulanciers paramédicaux et de $3,35 / 5$ chez les étudiants en technique paramédicale $(p=0,06)$.

Conclusions: Les ambulanciers paramédicaux et les étudiants en technique paramédicale préfèrent la pensée rationnelle à la pensée expérientielle, et ils se sentent capables de l'utiliser.

From the *Emergency Health Services, Dartmouth, NS; †Department of Emergency Medicine and Division of EMS, Dalhousie University, Halifax, NS; ¥McMaster University Family Medicine Residency Program, Hamilton, ON; §Ottawa Hospital Research Institute, Ottawa, ON; and $\uparrow$ Centennial College, Toronto, ON.

Correspondence to: Jan L. Jensen, Emergency Health Services, Performance and Development, 239 Brownlow Avenue, Suite 300, Dartmouth, NS, B3B2B2E; Email: Jan.Jensen@emci.ca 
Les résultats viennent enrichir les connaissances actuelles sur les prises de décision par les ambulanciers paramédicaux, et pourraient se montrer utiles dans l'élaboration d'outils de formation continue et d'aide clinique.
Keywords: emergency medical services, paramedics, decision making

\section{INTRODUCTION}

It is widely accepted that near-miss and adverse events occur during the process of delivering care to patients in the in-hospital setting. ${ }^{1,2}$ Some of these events can likely be attributed to lapses in paramedic judgment and decision-making. ${ }^{3-5}$ As with other health professions, it is important to understand how paramedics make decisions so that adverse events related to clinical judgment can be reduced or prevented.

The leading theory to explain how clinicians engage in clinical decision-making is the Dual Process Theory. ${ }^{6}$ Dual Process Theory suggests that decisions are made using one of two thinking systems (Table 1). System I is rapid and subconscious, and is often referred to as intuitive or experiential thinking. System II is conscious and deliberate, and is often referred to as rational thinking. ${ }^{7}$ The Rational Experiential Inventory-40 (REI-40) is a psychometric survey tool developed to identify thinking style preferences. ${ }^{8}$ The REI-40 is designed to measure ability to use and favourability towards each of the two major styles of decision-making: experiential (Type I) and rational (Type II).

Clinical decision-making styles have been studied in a number of populations, including United States university

\begin{tabular}{lll|}
$\begin{array}{l}\text { Table 1. Dual Processing Theory of clinical decision-making } \\
\text { (adapted from Croskerry, 20097) }\end{array}$ \\
\hline \multicolumn{3}{|l}{ System I } \\
Characteristic & $\begin{array}{l}\text { (Experiential) } \\
\text { Cognitive style }\end{array}$ & System II (Rational) \\
Awareness & Low & Analytical/systematic \\
Conscious control & Low & High \\
Automaticity & High & High \\
Cost/effort & Low & Low \\
Rate & Fast & High \\
Reliability & Low & Slow \\
Errors & Vulnerable to error & High \\
Predictive power & Low but large \\
Emotional valence & High & High \\
Detail on judgment & Low & Low \\
process & & High \\
Scientific rigour & Low & High \\
\hline
\end{tabular}

students, ${ }^{8}$ New Zealand cardiologists, ${ }^{9}$ and Canadian emergency physicians, ${ }^{10}$ but to date decision-making styles have not been studied in paramedics or paramedic student populations. Paramedic clinical decision-making is arguably unique compared to other professions, as paramedics practice in variable locations, are presented with a wide variety of unpredictable patient conditions, and often have few resources other than their partner. Moreover, how paramedics make decisions may play a large role in the safety and effectiveness of the care they deliver. ${ }^{11}$ Paramedics may tend to use one thinking strategy more than the other in most circumstances. For example, when presented with a middle-aged male with flank pain, a paramedic may employ experiential or intuitive thinking by immediately assigning a working diagnosis of renal colic through matching the patient's presentation to an illness script developed from previous observations of similar patients. Another paramedic, faced with the same patient, may tend more towards rational thinking, consciously working through other alternatives, such as aortic aneurysm, before assigning a provisional diagnosis and commencing down a treatment path. Given the increasing scope of paramedic practice ${ }^{12}$ and expanded roles and settings in which paramedics can now work (for example, involving community paramedicine initiatives), ${ }^{13}$ understanding how paramedics think and whether thinking styles change with work experience has the potential to help inform early and ongoing education and the development of paramedic training modules and clinical aides.

The objective of this study was to determine paramedic and paramedic student preferences toward, and perceived ability to use, experiential and rational thinking styles, and to determine whether thinking styles differ between these two groups.

\section{METHODS}

\section{Study design}

A cross-sectional paper-based survey was undertaken in Nova Scotia, Canada, to determine decision-making styles of two populations: 1) working ground ambulance paramedics, and 2) student paramedics at entry to 
practice level. The study was reviewed and approved by the Capital District Health Authority Research Ethics Board and the research ethics boards of participating paramedic colleges. Consent to participate was implied through submission of completed or partially completed surveys.

\section{Study setting and population}

Emergency medical services (EMS) in the study region is delivered by a single service with an annual call volume of approximately 70,000 calls, involving approximately 1,100 registered ground ambulance paramedics, who serve an a urban, suburban, and rural population of approximately one million people. EMS staff in the study region consisted of primary care paramedics (PCPs, 49\%), intermediate care paramedics (ICPs, 12\%), and advanced care paramedics (ACPs, $39 \%)$. The survey was administered to paramedics at mandatory in-service classroom professional development sessions held between May 1 and June 15, 2012.

PCP students from 15 colleges in Nova Scotia, New Brunswick, and Ontario were invited to participate in the study during their last week of training in 2013. Approximately 375 students were registered in PCP programs at the time of the survey.

Potential participants were given a survey and a blank envelope. Trainers or school faculty members distributed the surveys using scripted instructions. Surveys were sealed in the envelopes by participants, and were then mailed directly to the principal investigator, ensuring that trainers and faculty remained blinded to the participation decision of any specific individual.

\section{Study protocol}

Permission for use of the REI-40 was obtained from the developer (personal communication, Dr. S. Epstein, January 21, 2012).

The survey instrument consisted of demographic questions and the REI-40. The REI-40 is a psychometric tool that has been validated to identify thinking styles in several populations to assess thinking strategy and preferences. The REI-40 has been found to be reliable (Cronbach's alpha 0.74-0.91) and consistent. ${ }^{8,10,14-16}$ It involves 40 questions that are scored on a five-point Likert scale from "Definitely False" to "Definitely True." Twenty of these questions assess each thinking style (rational or experiential), of which 10 assess favourability towards a style and 10 assess ability to use a style. Higher scores indicate a higher affinity for the style in question. Participants were instructed to consider decisions made in their EMS clinical work rather than in their general everyday life (see Appendix). The English survey was translated to French by a professional translator and participants in bilingual regions were free to choose the language in which they preferred to respond.

The survey was pilot tested with 24 paramedics for face validity and was found to require approximately 15 minutes to complete. Based on pilot testing feedback, minor revisions were made to the demographic questions and format. Data were entered by a single investigator $(\mathrm{AB})$ for the working paramedic group and by a research assistant for the student group. Every tenth record was checked against the original by another investigator (JLJ) for accuracy of data entry.

\section{Data analysis}

The REI-40 was scored based on a coding manual provided by the lead investigator of the instrument (personal communication, Dr. S. Epstein, February 21, 2012). Coding included identifying the questions which addressed each of: Rational Ability, Rational Favourability, Experiential Ability, and Experiential Favourability (10 questions each). The responses for negatively-worded questions were reverse scored. The responses for questions in each category were summed and divided by 10 for the average score for each participant for each category. Analysis included descriptive statistics and $t$ tests to determine differences in overall thinking style scores within and between groups. Within each group, differences in favourability towards and ability to use each style were also evaluated with $t$ tests. If more than three responses per set of 20 questions for a thinking style were missing in a survey, that survey was excluded from analysis. For surveys with three or fewer missing responses per set of thinking style questions, any missing responses were replaced with the mode of the remaining responses for that style (personal communication, Dr. S Epstein, July 30, 2012). Differences in thinking styles within demographic variables were evaluated with $t$ tests and ANOVA. Significance ( $p$ value) was established at 0.05 for all tests, with corrections for multiple comparisons (with Hochberg's GT2 procedure for categories with different sample sizes, and Games-Howell procedure 
for uncertainty of population variances of categories as appropriate), and the most conservative resulting $p$ values were reported.

\section{RESULTS}

Paramedics from the aforementioned single EMS service and paramedic students from fifteen colleges participated, with a response rate of 1172/1263 (88.4\%) (Figure 1). 1,206 surveys were received, including 32 that had missing data and were excluded (2.6\%) and two where the respondents indicated they did not wish to participate. During data quality review, 10 records of 117 (8.5\%) had minor data entry errors, which were corrected.

Paramedic student participants were younger than paramedic participants; there was a higher percentage of female participants among students than among paramedics. Of the paramedic participants $(n=904)$, most were male $(69.5 \%)$, the median age was 36 , most were PCPs (55.5\%) and ACPs (32.5\%), and the median years of experience was 10 years (Table 2). Among student paramedic $(n=268)$, the median age was 23 years, most were male $(63.1 \%)$, most completed their training in Ontario $(76.1 \%)$, and most had completed high school $(31.7 \%)$ or an undergraduate degree (25.4\%) prior to paramedic training.

Overall, paramedics scored questions on rational thinking style higher than experiential thinking style (3.86/5 vs. $3.41 / 5, p<0.001$ ), perceived that they were better able to use rational thinking than experiential thinking $(3.93 / 5$ vs. $3.60 / 5, p<0.001)$, and indicated that they preferred to use rational thinking over experiential thinking $(3.79 / 5$ vs. $3.22 / 5, p<0.001)$ (Table 3). Paramedics who were male $(p=0.02)$, younger $(p<0.001)$, Advanced Care Paramedics $(p=0.001)$, or had fewer years working experience $(p=0.001)$ or years since last training $(p<0.001)$ and who worked in urban or a mix of urban-rural settings $(p=0.001)$ scored higher on rational questions than their counterparts. No differences were found between demographic strata in rational thinking scores categorized by the type of paramedic training completed or hours worked per week. There were no differences found between strata in any demographic for scores on experiential thinking. (Table 4)

Overall, paramedic students also scored rational thinking style questions higher than experiential thinking style questions $(3.97 / 5$ vs. $3.35 / 5, p<0.001)$, perceived that they were better able to use rational

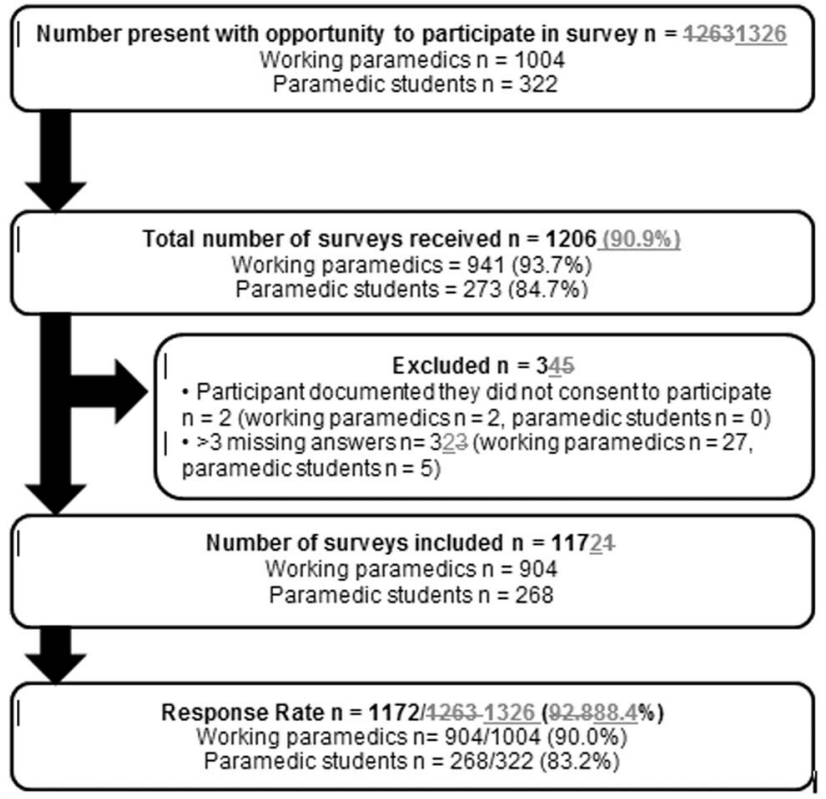

Figure 1. Flow of working paramedic and student paramedic survey responses. N: number.

thinking than experiential thinking (4.03/5 vs. $3.55 / 5$, $p<0.001)$, and indicated that they preferred to use rational thinking over experiential thinking (3.90/5 vs. $3.16 / 5, p<0.001)$. Rational thinking style questions were given higher scores by paramedic students who were younger $(p=0.04)$ and who had more prior education $(p<0.01)$ compared with their counterparts. Similar to the situation with paramedics, no differences were found between any demographic for experiential thinking scores.

When all participants' scores were grouped for age and gender, no difference was found in rational thinking scores between males and females $(p=0.54)$. Males were found to score experiential thinking lower than females $(p<0.001)$. Younger participants were more likely to score rational thinking higher than older participants $(p<0.001)$; however, no difference was found in experiential thinking scores by age (Table 5 ).

\section{DISCUSSION}

In this study we used the REI-40 to determine paramedic and paramedic student preferences toward and perceived ability to use experiential and rational thinking styles in the context of their clinical work, and to determine whether thinking styles differed between these two groups. Scores for rational thinking were higher than experiential thinking in both groups, 
Paramedic decision-making

Table 2. Characteristics of working paramedic and student paramedic participants.

\begin{tabular}{|c|c|c|c|}
\hline Demographics & Working Paramedics n = 904 n (\%) & Student Paramedics $n=268 n(\%)$ & Difference $p$ \\
\hline Gender & & & 0.001 \\
\hline Male & $628(69.5)$ & $169(63.1)$ & \\
\hline Missing data & $10(1.1)$ & $5(1.9)$ & \\
\hline Age in Years & Median: 36 (IQR 29-42) & Median: 23 (IOR 21-26) & 0.001 \\
\hline 16-19 & $2(0.2)$ & $11(4.1)$ & \\
\hline $20-29$ & $224(24.8)$ & $221(82.5)$ & \\
\hline $30-39$ & $335(37.1)$ & $25(9.3)$ & \\
\hline $40-49$ & $232(25.7)$ & $6(2.2)$ & \\
\hline $50-59$ & $64(7.1)$ & $1(0.4)$ & \\
\hline $60+$ & $3(0.3)$ & $0(0)$ & \\
\hline Missing data & $44(4.9)$ & $4(1.5)$ & \\
\hline Paramedic Level & & $\mathrm{n} / \mathrm{a}$ & \\
\hline EMD & $3(0.3)$ & & \\
\hline PCP & $502(55.5)$ & & \\
\hline $\mathrm{ICP}$ & $82(9.1)$ & & \\
\hline $\mathrm{ACP}$ & $294(32.5)$ & & \\
\hline $\mathrm{CCP}$ & $9(1.0)$ & & \\
\hline Missing data & $14(1.5)$ & & \\
\hline Years of Experience & Median 10 (IQR 4-16) & $\mathrm{n} / \mathrm{a}$ & \\
\hline $0-1$ & $93(10.3)$ & & \\
\hline $2-5$ & $156(17.3)$ & & \\
\hline $6-10$ & $187(20.7)$ & & \\
\hline $11-19$ & $242(26.8)$ & & \\
\hline $20+$ & $142(15.7)$ & & \\
\hline Missing data & $84(9.3)$ & & \\
\hline Years Since Last Training & Median 6 (IQR 2.5-11) & $\mathrm{n} / \mathrm{a}$ & \\
\hline $0-1$ & $132(14.6)$ & & \\
\hline $2-5$ & $247(27.3)$ & & \\
\hline $6-10$ & $213(23.6)$ & & \\
\hline $11+$ & $213(23.6)$ & & \\
\hline Missing data & $99(11.0)$ & & \\
\hline \multicolumn{4}{|l|}{ Type of Paramedic Training } \\
\hline Full-time & $643(71.1)$ & $253(94.4)$ & \\
\hline Part-time or distance & $158(17.5)$ & $14(5.2)$ & \\
\hline Other & $52(5.8)$ & $0(0.0)$ & \\
\hline Missing data & $51(5.6)$ & $1(0.4)$ & \\
\hline EMS Work Setting* & & $\mathrm{n} / \mathrm{a}$ & \\
\hline Urban & $222(24.6)$ & & \\
\hline Rural & $367(40.6)$ & & \\
\hline Mix of urban and rural & $291(32.2)$ & & \\
\hline Missing data & $24(2.6)$ & & \\
\hline Average Hours Worked Per Week & Median 42 IQR (42-48) & $\mathrm{n} / \mathrm{a}$ & \\
\hline $0-36$ & $56(6.2)$ & & \\
\hline $37-60$ & $754(83.4)$ & & \\
\hline $61+$ & $35(3.9)$ & & \\
\hline Education Prior to PCP Training & $\mathrm{n} / \mathrm{a}$ & & \\
\hline High School & & $85(31.7)$ & \\
\hline Certificate & & $52(19.4)$ & \\
\hline Diploma & & $44(16.4)$ & \\
\hline Undergraduate Degree & & $68(25.4)$ & \\
\hline Graduate Degree & & $1(0.4)$ & \\
\hline $\mathrm{PhD}$ & & $1(0.4)$ & \\
\hline Other & & $13(4.9)$ & \\
\hline Missing data & & $4(1.5)$ & \\
\hline \multicolumn{4}{|l|}{ Province } \\
\hline Nova Scotia & $904(100)$ & $43(16.0)$ & \\
\hline New Brunswick & & $20(7.5)$ & \\
\hline Ontario & & $204(76.1)$ & \\
\hline Missing data & & $1(0.4)$ & \\
\hline
\end{tabular}


suggesting that both paramedics and paramedic students perceived that they had the ability to use rational more than experiential thinking and that they preferred rational over experiential thinking. Our results are consistent with studies involving cardiologists and emergency physicians (Table 6)., ${ }^{9,10}$ However, our results differ from American college students, who were found to score higher on experiential thinking. ${ }^{8}$

\begin{tabular}{|c|c|c|c|}
\hline & $\begin{array}{c}\text { Rational Score } \\
\text { mean (SD) }\end{array}$ & $\begin{array}{c}\text { Experiential Score } \\
\text { mean (SD) }\end{array}$ & $p$ \\
\hline \multicolumn{4}{|l|}{ Paramedics } \\
\hline Mean Score & $3.86(0.42)$ & $3.41(0.42)$ & $<0.001$ \\
\hline $\begin{array}{l}\text { Mean Ability } \\
\text { Scores }\end{array}$ & $3.93(0.43)$ & $3.60(0.41)$ & $<0.001$ \\
\hline $\begin{array}{l}\text { Mean } \\
\text { Favourability } \\
\text { Scores }\end{array}$ & 3.7910 .49 & $3.22(0.51)$ & $<0.001$ \\
\hline $\begin{array}{l}\text { Paramedic } \\
\text { Students }\end{array}$ & & & \\
\hline Mean Score & $3.97(0.41)$ & $3.35(0.46)$ & $<0.001$ \\
\hline $\begin{array}{l}\text { Mean Ability } \\
\text { Scores }\end{array}$ & $4.03(0.45)$ & $3.55(0.46)$ & $<0.001$ \\
\hline $\begin{array}{l}\text { Mean } \\
\text { Favourability } \\
\text { Scores }\end{array}$ & $3.90(0.48)$ & $3.16(0.56)$ & $<0.001$ \\
\hline
\end{tabular}

In this study, both participant groups scored experiential and intuitive thinking higher than the mid-point of the scale, indicating they likely used both thinking strategies. The Dual Processing Theory suggests that System II (rational) thinking may have a "supervisory" role over System I (experiential), and that clinicians with critical thinking move between the two systems efficiently, a skill that has been described as the ability to "calibrate" one's thinking. ${ }^{7}$ A similar activity has been postulated in nurses, a group that has traditionally viewed intuition to be a hallmark trait of expert clinicians, ${ }^{17-19}$ although a recent review found that nurses placed equal emphasis on experiential and rational thinking and concluded that nurses likely use a mix of both styles in practice. ${ }^{20}$

While it is unknown specifically which thinking style or particular strategy is superior for different clinical situations, paramedics and paramedic students can become more aware of their thinking style and can be trained in the benefits and pitfalls of each thinking style. $^{21,22}$ Errors in the decision-making process represent a threat to the delivery of appropriate prehospital care and thus a threat to patient safety. ${ }^{23}$ We feel that training on the decision-making process and thinking styles should be included in the National Occupational Competency Profile, a resource that defines the required content for foundational paramedic training in Canada. ${ }^{24}$ Clinical decision-making education modules could include topics such as understanding meta-cognition and the Dual Processing Theory, understanding and appropriate use of various

Table 4. Mean rational and experiential scores by working paramedics group and student paramedics group; and gender and age data for all study participants.

\begin{tabular}{|c|c|c|c|c|c|}
\hline & Number of Participants (n) & Rational Scores mean (SD) & $p$ & Experiential Scores mean (SD) & $p^{*}$ \\
\hline Working Paramedics & 904 & $3.86(0.42)$ & $<0.001$ & $3.41(0.42)$ & 0.06 \\
\hline Student Paramedics & 267 & $3.97(0.42)$ & & $3.36(0.46)$ & \\
\hline \multicolumn{6}{|c|}{ Gender: All Participants } \\
\hline Male & 798 & $3.89(0.44)$ & 0.54 & $3.36(0.42)$ & $<0.001$ \\
\hline Female & 362 & $3.87(0.38)$ & & $3.48(0.43)$ & \\
\hline \multicolumn{6}{|c|}{ Age in Years: All Participants } \\
\hline $16-19$ & 13 & $4.12(0.47)$ & $<0.001$ & $3.26(0.58)$ & 0.30 \\
\hline $20-29$ & 445 & $3.96(0.39)$ & & $3.38(0.43)$ & \\
\hline $30-39$ & 360 & $3.87(0.42)$ & & $3.44(0.42)$ & \\
\hline $40-49$ & 238 & $3.85(0.44)$ & & $3.39(0.42)$ & \\
\hline $50-59$ & 65 & $3.64(0.40)$ & & $3.36(0.46)$ & \\
\hline $60+$ & 3 & $3.62(0.10)$ & & $3.60(0.48)$ & \\
\hline
\end{tabular}




\begin{tabular}{|c|c|c|c|c|c|}
\hline Demographic Strata & $n$ & Rational Scores mean (SD) & $p$ & Experiential Scores mean (SD) & $p$ \\
\hline \multicolumn{6}{|l|}{ Working Paramedics } \\
\hline \multicolumn{6}{|l|}{ Gender } \\
\hline Male & 628 & $3.86(0.43)$ & \multirow[t]{2}{*}{0.02} & $3.67(0.41)$ & \multirow[t]{2}{*}{0.86} \\
\hline Female & 266 & $3.86(0.38)$ & & $3.51(0.42)$ & \\
\hline \multicolumn{3}{|l|}{ Age in Years } & \multirow[t]{7}{*}{$<0.001$} & & \multirow[t]{7}{*}{0.13} \\
\hline $16-19$ & 2 & $3.98(1.03)$ & & $2.80(0.42)$ & \\
\hline $20-29$ & 224 & $3.96(0.39)$ & & $3.42(0.42)$ & \\
\hline $30-39$ & 335 & $3.85(0.41)$ & & $3.44(0.40)$ & \\
\hline $40-49$ & 232 & $3.85(0.44)$ & & $3.39(0.42)$ & \\
\hline $50-59$ & 64 & $3.64(0.40)$ & & $3.36(0.46)$ & \\
\hline $60+$ & 3 & $3.62(0.10)$ & & $3.60(0.48)$ & \\
\hline \multicolumn{3}{|l|}{ Paramedic Level } & \multirow[t]{6}{*}{0.001} & & \multirow[t]{6}{*}{0.32} \\
\hline EMD & 3 & $3.93(0.41)$ & & $3.08(0.68)$ & \\
\hline PCP & 502 & $3.83(0.42)$ & & $3.41(0.39)$ & \\
\hline ICP & 82 & $3.74(0.41)$ & & $3.46(0.39)$ & \\
\hline$A C P$ & 294 & $3.94(0.41)$ & & $3.42(0.47)$ & \\
\hline $\mathrm{CCP}$ & 9 & $3.84(0.19)$ & & $3.23(0.43)$ & \\
\hline \multicolumn{3}{|l|}{ Years of Experience } & \multirow[t]{6}{*}{0.001} & & \multirow[t]{6}{*}{0.70} \\
\hline $0-1$ & 93 & $3.97(0.35)$ & & $3.36(0.39)$ & \\
\hline $2-5$ & 156 & $3.92(0.40)$ & & $3.42(0.48)$ & \\
\hline $6-10$ & 187 & $3.88(0.40)$ & & $3.43(0.41)$ & \\
\hline $11-19$ & 242 & $3.84(0.42)$ & & $3.43(0.41)$ & \\
\hline $20+$ & 142 & $3.77(0.48)$ & & $3.41(0.41)$ & \\
\hline \multicolumn{2}{|l|}{ Years Since Last Training } & & \multirow[t]{5}{*}{$<0.001$} & & \multirow[t]{5}{*}{0.91} \\
\hline $0-1$ & 132 & $3.99(0.37)$ & & $3.40(0.41)$ & \\
\hline $2-5$ & 247 & $3.92(0.40)$ & & $3.42(0.46)$ & \\
\hline $6-10$ & 213 & $3.89(0.42)$ & & $3.43(0.41)$ & \\
\hline $11+$ & 213 & $3.76(0.42)$ & & $3.44(0.39)$ & \\
\hline Type of Paramedic Trainin & & & 0.41 & & 0.79 \\
\hline Full-time & 643 & $3.86(0.42)$ & & $3.42(0.42)$ & \\
\hline Part-time or distance & 158 & $3.87(0.41)$ & & $3.40(0.41)$ & \\
\hline Other & 52 & $3.93(0.45)$ & & $3.39(0.43)$ & \\
\hline EMS Work Setting & & & 0.001 & & 0.62 \\
\hline Urban & 222 & $3.93(0.39)$ & & $3.40(0.42)$ & \\
\hline Rural & 367 & $3.80(0.42)$ & & $3.41(0.39)$ & \\
\hline Mix of urban and rural & 291 & $3.88(0.43)$ & & $3.43(0.44)$ & \\
\hline Average Hours Worked P & & & 0.24 & & 0.09 \\
\hline $0-36$ & 56 & $3.95(0.40)$ & & $3.29(0.41)$ & \\
\hline $37-60$ & 754 & $3.85(0.42)$ & & $3.42(0.42)$ & \\
\hline $61+$ & 35 & $3.84(0.41)$ & & $3.42(0.38)$ & \\
\hline Student Paramedics & & & & & \\
\hline Gender & & & & & \\
\hline Male & 170 & $4.00(0.43)$ & 0.52 & $3.34(0.47)$ & 0.39 \\
\hline Female & 96 & $3.90(0.38)$ & & $3.39(0.44)$ & \\
\hline Age in Years & & & & & \\
\hline $16-19$ & 11 & $4.14(0.39)$ & 0.04 & 3.34 & 0.98 \\
\hline $20-29$ & 221 & $3.96(0.40)$ & & 3.35 & \\
\hline $30-39$ & 25 & $4.07(0.44)$ & & 3.38 & \\
\hline $40-49$ & 6 & $3.74(0.44)$ & & 3.47 & \\
\hline $50-59$ & 1 & 3.10 & & 3.40 & \\
\hline $60+$ & 0 & & & & \\
\hline Previous Education & & & & & \\
\hline High School & 85 & $3.89(0.36)$ & 0.01 & $3.30(0.43)$ & 0.26 \\
\hline Certificate & 52 & $4.00(0.45)$ & & $3.45(0.50)$ & \\
\hline Diploma & 44 & $3.91(0.47)$ & & $3.36(0.43)$ & \\
\hline Undergraduate & 68 & $4.05(0.34)$ & & $3.31(0.47)$ & \\
\hline Graduate & 1 & $4.65(-)$ & & $4.20(-)$ & \\
\hline $\mathrm{PhD}$ & 1 & $3.10(-)$ & & $3.40(-)$ & \\
\hline Other & 13 & $4.15(0.54)$ & & $3.45(0.50)$ & \\
\hline
\end{tabular}




\begin{tabular}{|c|c|c|c|}
\hline Population & $\mathrm{n}$ & Mean Rational Score (SD) & Mean Experiential Score (SD) \\
\hline Nova Scotia Ground Ambulance Paramedics & 904 & $3.86(0.42)$ & $3.41(0.42)$ \\
\hline Student Paramedics (Nova Scotia, New Brunswick, Ontario) & 268 & $3.97(0.41)$ & $3.35(0.46)$ \\
\hline Ontario Emergency Physicians ${ }^{9}$ & 434 & $3.93(0.35)$ & $3.33(0.49)$ \\
\hline New Zealand Cardiologists ${ }^{8}$ & 74 & $3.93(0.37)$ & $3.05(0.53)$ \\
\hline United States College Students ${ }^{6}$ & 399 & $3.39(0.61)$ & $3.52(0.47)$ \\
\hline
\end{tabular}

decision-making strategies (ranging from exhaustive to ruling out the worst case scenario to algorithmic), awareness of cognitive biases, and ensuring knowledge of cognitive error-avoiding strategies. ${ }^{25,26}$ Similarly, continuing education opportunities for paramedics could include clinical decision-making. Case presentations are a common quality assurance practice in many EMS services and are suitable for adaptation to a "cognitive autopsy" style of case review, which includes a focus on the thinking strategies used and the internal and external factors that may have affected paramedic decisionmaking. ${ }^{25}$ Simulation, another common continuing education tool for paramedics, could be structured such that selected simulated cases were run as "think aloud" scenarios. In such an approach, participants are prompted to stop at each decision point and discuss the decision made, why they made it, and what thinking strategy was used. ${ }^{27}$ Strategies of this nature have the potential to raise paramedics' awareness of their own thinking and cognitive errors. Our findings and their implications may be particularly timely given the increasing paramedic scope of practice in Canada, expanded scope roles, and movement away from linear algorithms in favour of guidelines. $^{28-31}$

The differences we found in scores between groups and between the demographic strata of each group suggest that preferences toward and ability to use each thinking style may evolve with age. Rational thinking scores were higher in the student paramedic group than the working paramedic group. In the working paramedic group, rational scores were higher among those who were younger, ACPs, working in urban or mixed urban-rural environments, and who had fewer years working experience. These findings may be attributable in part to more previous education (e.g., undergraduate degrees) and ACP training among younger paramedics - both of which emphasize decision-making skills—and the increased likelihood of working in an urban area when beginning a career in paramedicine. Alternatively or in addition, they may reflect a secular change in the nature of paramedic education. In contrast with a previous study wherein female health care professionals were found to score higher on experiential thinking than their male counterparts, ${ }^{10}$ we found that male paramedics scored experiential thinking higher than did females, suggesting that male paramedics tend more towards intuitive thinking. This finding could, however, be a function of experience rather than gender, as there were more male paramedics in older age groups and with more years of EMS experience than females. Our findings are important to consider in paramedic continuing education and the design of cognitive aids, as they suggest paramedics do not uniformly tend to value or use an identical thinking strategy. This finding provides further support for the notion that incorporating awareness of decision-making into paramedic clinical education may provide an essential awareness that helps practitioners refine their own cognitive practices.

\section{LIMITATIONS}

The most significant limitation of this study is that REI-40 captures self-reported perception of ability to use, and preference toward, rational and experiential thinking, and may therefore not be an accurate representation of thinking style in actual clinical settings. Unlike other tools, such as pain scales, a meaningful important difference in scores has not been established for the REI-40; as a result it is difficult to know whether the differences in scores in our study represent an important difference in thinking. For this reason, we provided comparison scores from other populations to give readers further context. Other potential limitations 
include response bias, such that some paramedics and paramedic students may have answered questions in the way they felt was socially desirable, or they felt investigators wished them to respond, or the way that was impressed upon them in their educational setting. However, we believe the effect of response bias would be minimal, as participants were not provided with any training in decision-making theory prior to completing the survey. Paramedics and students were clearly instructed that their participation was voluntary; however, our high response rate could suggest paramedics may have completed the survey simply because it was delivered during a professional development session, and paramedic students may have completed the survey because it was distributed during class time. We carefully inspected all received surveys for any comments indicating the paramedic or student did not voluntarily agree to participate, and as a result two participants were excluded. Differences existed in demographic characteristics between the paramedic and paramedic student groups regarding gender, age, and training. It is possible that one or more of these factors had a significant influence on reported thinking style, rather than work experience, and our lack of a multivariate analysis methodology makes it impossible to determine whether or not this is the case. The working paramedic sample was entirely from Nova Scotia, potentially limiting the generalizability to paramedics trained in and working in other systems. While we do not believe there are significant differences with other Canadian paramedics, it is possible that recent focus on clinical practice guidelines and other related topics in the targeted study setting may have affected responses from our paramedic sample. The majority of paramedic students in our study population were from Ontario and had not been exposed to the Nova Scotia EMS system, so it is noteworthy that they scored rational thinking higher than the working paramedic group. This may suggest that rational thinkers self-select to become paramedics, regardless of setting.

Future studies could focus on determining how to assess decision-making in training, identifying the optimal thinking style for specific clinical scenarios, identifying the thinking style and other characteristics of paramedics who are expert practitioners, determining if paramedics can be taught these optimal thinking strategies to apply to given clinical scenarios, and the development of cognitive aids tailored towards specific thinking styles. ${ }^{26,28,31,32}$

\section{CONCLUSION}

In this cross-sectional survey of ground ambulance paramedics in a provincial EMS system and primary care paramedic students at entry to practice level, we found paramedics and paramedic students prefer and perceive that they have the ability to use rational over experiential thinking. This information adds to our current knowledge on paramedic decision-making and is potentially important for developing continuing education and clinical support tools.

Competing Interests: None to declare.

\section{SUPPLEMENTARY MATERIAL}

To view supplementary material for this article, please visit http://dx.doi.org/10.1017/cem.2015.95

\section{REFERENCES}

1. Kohn LT, Corrigan JM, Molla S. To Err Is Human: Building a Safer Health System. Committee on Quality of Health Care in America. Washington DC: Institute of Medicine National Academy Press; 1999.

2. Baker GR, Norton PG, Flintoft V, et al. The Canadian Adverse Events Study: the incidence of adverse events among hospital patients in Canada. CMAJ 2004; 170(11):1678-86.

3. Graber ML, Franklin N, Gordon R. Diagnostic error in internal medicine. Arch Intern Med 2005;165(13):1493-9.

4. Calder L, Tierney S, Jiang Y, et al. Patient safety analysis of the ED care of patients with heart failure and COPD exacerbations: a multicenter prospective cohort study. $A m \mathcal{F}$ Emerg Med 2014;32(1):29-35.

5. Calder LA, Forster A, Nelson M, et al. Adverse events among patients registered in high-acuity areas of the emergency department: a prospective cohort study. CFEM 2010;12(5):421-30.

6. Norman G. Dual processing and diagnostic errors. Adv Health Sci Educ Theory Pract 2009;14(Suppl 1):37-49.

7. Croskerry P. A universal model of diagnostic reasoning. Acad Med 2009;84(8):1022-8.

8. Pacini R, Epstein S. The relation of rational and experiential information processing styles to personality, basic beliefs, and the ratio-bias phenomenon. $\mathcal{F}$ Pers Soc Psychol 1999; 76(6):972-87.

9. Sladek RM, Bond MJ, Huynh LT, et al. Thinking styles and doctors' knowledge and behaviours relating to acute coronary syndromes guidelines. Implement Sci 2008;3:23.

10. Calder LA, Forster AJ, Stiell IG, et al. Experiential and rational decision making: a survey to determine how emergency physicians make clinical decisions. Emerg Med 7 2012;29(10):811-6. 
11. Bigham BL, Maher J, Brooks SC, et al. Patient safety in emergency medical services: advancing and aligning the culture of patient safety in EMS. Edmonton, AB: Canadian Patient Safety Institute; 2010.

12. Paramedic Association of Canada. National Occupational Competency Profile, Area 1: Professional Responsibilities. Available at: http://paramedic.ca/nocp/nocp_professional responsibilities/ (accessed September 26, 2012).

13. Jensen JL, Travers AH, Bardua DJ, et al. Transport outcomes and dispatch determinants in a paramedic long-term care program: a pilot study. CFEM 2013;15(4):206-13.

14. Björklund F, Bäckström $M$. Individual differences in processing styles: validity of the Rational-Experiential Inventory. Scand 7 Psychol 2008;49(5):439-46.

15. Witteman C, van den Bercken J, Claes L, et al. Assessing rational and intuitive thinking styles. Eur 7 Psychol Assess 2009;25(1):39-47.

16. Shiloh S, Salton E, Sharabi D. Individual differences in rational and intuitive thinking styles as predictors of heuristics responses and framing effects. Pers Individ Dif 2002;32(3):415e29.

17. Carper B. Fundamental patterns of knowing in nursing. ANS Adv Nurs Sci 1978;1(1):13-23.

18. Benner P. From Novice to Expert: Excellence and Power in Clinical Nursing practice. Menlo Park, CA: Addison-Wesley; 1984.

19. White J. Patterns of knowing: review, critique and update. ANS Adv Nurs Sci 1995;17(4):73-86.

20. Paley J, Cheyne H, Dalgleish L, et al. Nursing's ways of knowing and dual process theories of cognition. 7 Adv Nurs 2007;60(6):692-701.

21. Graber ML. Educational strategies to reduce diagnostic error: Can you teach this stuff? Adv Health Sci Educ Theory Pract 2009;14(Suppl 1):63-9.

22. Ericsson KA, Nandagopal K, Roring RW. Toward a science of exceptional achievement: Attaining superior performance through deliberate practice. Ann N Y Acad Sci 2009;1172:199-217.
23. Hagiwara MA, Suserud BO, Andersson-Gare B, et al. The effect of a computerized decision support system (CDSS) on compliance with the prehospital assessment process: results of an interrupted time-series study. BMC Med Inform Decis Mak 2014;14:70.

24. Paramedic Association of Canada. National Occupational Competency Profile. Available at: http://www.paramedic.ca/ site/nocp? nav $=02$ (accessed November 2, 2015).

25. Croskerry P. Diagnostic failure: a cognitive and affective approach. In: Advances in Patient Safety: From Research to Implementation (Volume 2: Concepts and Methodology) (eds. Henriksen K, Battles JB, Marks ES, et al.). Rockville: Agency for Healthcare Research and Quality; 2005, 241-52. Available from: http://www.ahrq.gov/qual/advances/ (accessed October 7, 2014).

26. McGregor CA, Paton C, Thomson C, et al. Preparing medical students for clinical decision making: a pilot study exploring how students make decisions and the perceived impact of a clinical decision making teaching intervention. Med Teach 2012;34(7):e508-17.

27. Skånér Y, Backlund L, Montgomery H, et al. General practitioners' reasoning when considering the diagnosis heart failure: a think-aloud study. BMC Fam Prac 2005; $6(1): 4$.

28. Jensen JL, Dobson T. Towards National EvidenceInformed Practice Guidelines for Canadian EMS: Future Directions. Healthc Policy 2011;7(1):22-31.

29. Province of Nova Scotia. Emergency Health Services. Available at: http://novascotia.ca/dhw/ehs/ (accessed October 2, 2012).

30. International Roundtable on Community Paramedicine. Future of EMS. Available at: http://ircp.info/Future-ofEMS (accessed October 2, 2012).

31. Prehospital Evidence Based Protocols Project. Canadian Prehospital Evidence Based Protocols. Available at: https:// emspep.cdha.nshealth.ca/ (accessed October 2, 2012).

32. Ericsson KA. An expert-performance perspective of research on medical expertise: the study of clinical performance. Med Educ 2007;41(12):1124-30. 